\title{
MECHANICAL DIFFERENTIAL MATHEMATICAL MODEL
}

The simulation of a road vehicle requires also the model of a mechanical differential. This article describes one of the possibilities how to build a mechanical differential model by the selected vehicle model structure.

Keywords: Simulation, mathematical model, mechanical differential.

\section{Introduction}

In cars and other double-tracked wheeled vehicles, a differential couples the drive shaft to half-shafts that connect to the front or rear driving wheels. The differential gearing allows the outer drive wheel to rotate faster than the inner drive wheel during a turn [1] and [2]. This is necessary when the vehicle turns, making the wheel that is travelling around the outside of the turning curve roll farther and faster than the other one. Average of the rotational speed of the two driving wheels equals the input rotational speed of the drive shaft. An increase in the speed of one wheel is balanced by a decrease in the speed of the other.

\section{Vehicle model concept}

Special blocks that enable sequencing and creating of string structures are also called two-terminal blocks. They have one input $\boldsymbol{i}$ and one output $\boldsymbol{o}$ on each side of the block (Fig. 1).

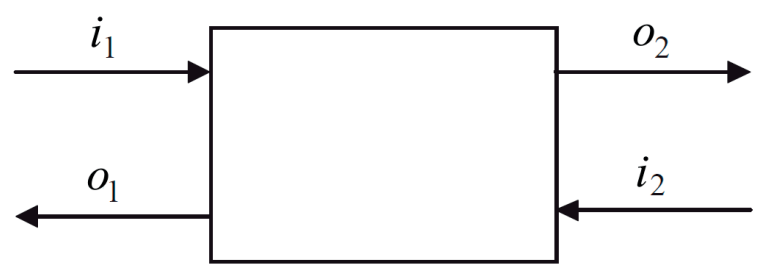

Fig. 1 Two-terminal block (Source: authors)

The principle of the string-concept vehicle modelling can be used by the classic drivetrain vehicle model, which consists from two-terminal block models of the drivetrain subsystems and the three-terminal block model of the rear axle mechanical differential (Fig. 2).

The vehicle drivetrain model consists of blocks which are connected in alternating order of the blocks defining inertias (engine, gearbox, differential, vehicle body, wheels) and the blocks defining the torque or force law between connected components (clutch, torque converter, elastic shafts, tire) [3] and [4].

The blocks can be then divided into two groups:

- inertia blocks with the inner structure defining the inertia of the engine, gearbox, differential, wheels and the car body, which calculate the component speed,

- torque and force blocks, which calculate the torque of the clutch (alt. torque converter), torque on the shaft ends and forces between the tires and the track or the wheels respectively.

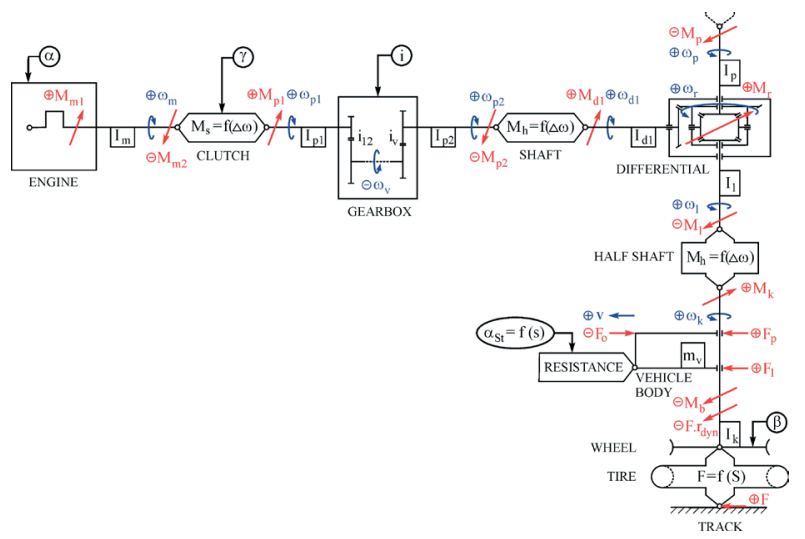

Fig. 2 Classic vehicle drivetrain model (Source: authors)

The string structure is completed with the:

- control parameter blocks (round shaped with the arrow towards the controlled block), which represent the position

\footnotetext{
* Frantisek Brumercik, Michal Lukac, Aleksander Nieoczym 
of the gas, brake and clutch pedal and the shifted gear according the driver discrete event system (DES) model [5],

- environment resistance block, which is defined by the track and vehicle characteristics (grade resistance) [6] or the environment (aerodynamic drag).

\section{Differential model structure}

A differential (Fig. 3) consists of one input, the drive (propeller) shaft, and two outputs - half shafts, which are connected to the drive wheels [7]. The rotation of the drive wheels are coupled by their connection to the track via the tires. Under normal conditions, with small tire slip, the ratio of the speeds of the two driving wheels is defined by the ratio of the radii of the paths around which the two wheels are rolling, which in turn is determined by the track-width of the vehicle (the distance between the driving wheels) and the radius of the turn.

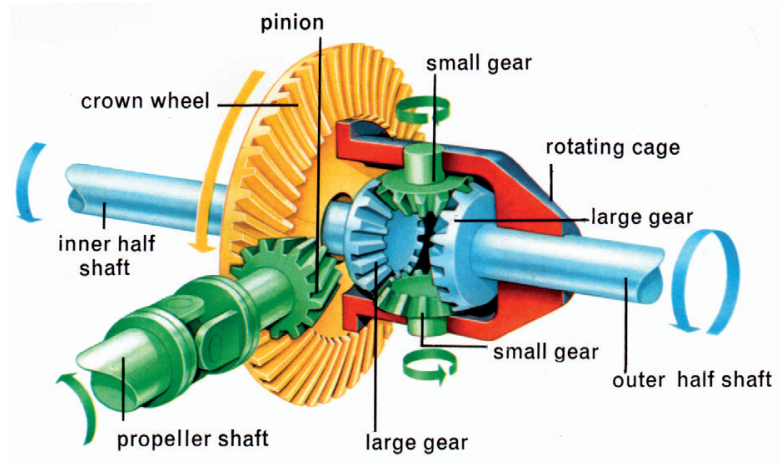

Fig. 3 Structure of a common vehicle mechanical differential (Source: http://www.mrclutchnw.com/services/differential-rebuilding/)

\section{Model equations}

The model of the differential has to be a three-terminal according to the vehicle drivetrain model structure described above (Fig. 4).

The kinematics of the three-shaft differential basic elements are defined according to the Willis formula as

$\omega_{p}-\omega_{l} u_{v}=\omega_{r}\left(1-u_{v}\right)$,

where: $\omega_{p}$ speed of the central wheel $p$,

$\omega_{l}$, speed of the central wheel $l$,

$\omega_{r}$ speed of the carrier $r$,

$u_{v}$ fundamental differential ratio.

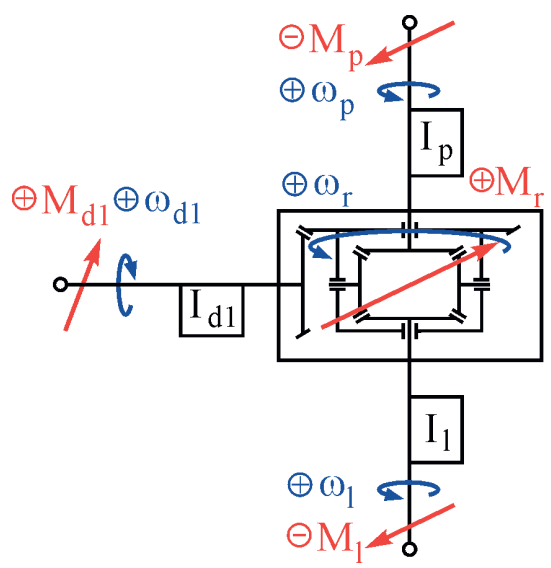

Fig. 4 Structure of the three-terminal differential block model

(Source: authors)

The fundamental differential ratio is defined as

$u_{v}= \pm \frac{z_{l}}{z_{p}}=\frac{\omega_{p}}{\omega_{l}} \mid \omega_{r}=0$

where: $\quad z_{l}$ tooth number of the central wheel $l$,

$z_{p}$ tooth number of the central wheel $p$.

The relations between the torques in the differential are descibed via the torque equilibrium equation

$M_{p}+M_{l}+M_{r}=0$,

where: $M_{p}$ torque on the central wheel $p$, $M_{l}$ torque on the central wheel $l$, $M_{r}$ torque on the carrier $r$.

The power equilibrium has to be applied in the same time. Then, if the efficiency losses are ignored, the power balance equation is defined as

$M_{p} \omega_{p}+M_{l} \omega_{l}+M_{r} \omega_{r}=0$,

which is modified by the stopped differential rotating cage carrier $r\left(\omega_{r}=0\right)$ into the form

$M_{p} \omega_{p}+M_{l} \omega_{l}=0$.

If the differential is the vehicle one $\left(z_{p}=z_{l}\right.$, opposite speed of the wheels $p$ and $l$ by the stopped carrier $r$ ), the fundamental differential ratio has the value $u_{v}=-1$. The Willis formula (1) is then changing to the form

$\omega_{p}+\omega_{l}=2 \omega_{r}$.

The speeds of both differential output shafts can be also calculated with the help of the rotation superposition [8] and [9]. The final speed equations are superposed from the speeds of both 
output shafts with the carrier connected to a fixed unit and the relative speed of the central wheels towards the stopped carrier The equation of the relative speeds is given by

$$
\omega_{p}=\omega_{r}+\omega_{p r}
$$$$
\omega_{l}=\omega_{r}+\omega_{l r}
$$

where: $\omega_{p r}$ relative speed of the central wheel $p$ towards the stopped carrier $r$,

$\omega_{l r}$ relative speed of the central wheel $l$ towards the stopped carrier $r$.

The equation above is the condition of the relation between the speed derivations (accelerations) in the form

$\dot{\omega}_{p}=\dot{\omega}_{r}+\dot{\omega}_{p r}$

$\dot{\omega}_{l}=\dot{\omega}_{r}+\dot{\omega}_{l r}$

The acceleration component $\dot{\omega}_{r}$ of the described fixed unit of both output shafts with the carrier rotating with the speed $\omega_{r}$ is applicable to derive from the motion equation [10]

$I_{d r} \dot{\omega}_{r}=M_{r}+M_{p}+M_{l}$,

where: $I_{d r}$ inertia of the differential fixed unit reduced to the carrier $r$.

Reduced moment of inertia $I_{d r}$ of the unit consisting of differential input shaft with the differential pinion, carrier with the differential crown wheel and both output half shafts is calculable via the mass and force reduction method comparing the reduced unit kinetic energy and the kinetic energy of the unit components as

$$
\begin{aligned}
& \frac{1}{2} I_{d r} \omega_{r}^{2}=\frac{1}{2} I_{d l} \omega_{d l}^{2}+\frac{1}{2} I_{p} \omega_{r}^{2}+\frac{1}{2} I_{l} \omega_{r}^{2}= \\
& =\frac{1}{2} I_{d l} i_{d}^{2} \omega_{r}^{2}+\frac{1}{2}\left(I_{p}+I_{l}\right) \omega_{r}^{2}
\end{aligned},
$$

where: $I_{\mathrm{d} 1}$ inertia of the pinion and the rotating cage (carrier) reduced to the differential input shaft,

$I_{p, l}$ inertia of the output (half) shafts $p$ and $l$,

$i_{d}$ ratio between the differential pinion and the crown wheel,

$\omega_{d l}$ differential input shaft speed (pinion speed),

$\omega_{r}$ differential crown wheel speed (rotating cage/carrier speed).

The ratio between the pinion and the crown wheel is defined by the equation

$i_{d}=\frac{\omega_{d l}}{\omega_{r}}$
The torque ratio between the pinion and the crown wheel is defined with no losses by the equation

$i_{d}=-\frac{M_{d 2}}{M_{d l}}=\frac{M_{r}}{M_{d l}}$,

where: $M_{d 2}$ reaction torque on the crown wheel.

The angular accelerations of the output shafts can be calculated by the following motion equations [8] and [9]:

$I_{p r} \dot{\omega}_{p r}=\left(I_{p}+\frac{I_{l}}{u_{v}^{2}}\right) \dot{\omega}_{p r}=M_{p}+\frac{M_{l}}{u_{v}}$,

$I_{l r} \dot{\omega}_{l r}=\left(I_{l}+I_{p} u_{v}^{2}\right) \dot{\omega}_{l r}=M_{l}+M_{p} u_{v}$

where: $I_{p r} \quad$ inertia of both output shafts reduced to the central wheel $p$ shaft,

$I_{l r} \quad$ inertia of both output shafts reduced to the central wheel $l$ shaft.

The final angular acceleration equations of the all three differential shafts by the help of equations (8) through (13) can be defined either general as

$$
\begin{aligned}
& \dot{\omega}_{p}=\dot{\omega}_{r}+\dot{\omega}_{p r}=\frac{M_{r}+M_{p}+M_{l}}{I_{d r}}+\frac{M_{p}+M_{l} u_{v}^{-1}}{I_{p r}} \\
& \dot{\omega}_{l}=\dot{\omega}_{r}+\dot{\omega}_{l r}=\frac{M_{r}+M_{p}+M_{l}}{I_{d r}}+\frac{M_{p}+M_{l} u_{v}}{I_{l r}} \\
& \dot{\omega}_{r}=\frac{\dot{\omega}_{p}+\dot{\omega}_{l}}{2}=\frac{M_{r}+M_{p}+M_{l}}{I_{d r}}
\end{aligned}
$$

or particular for the vehicle differential $\left(u_{v}=-1 ; I_{p}=I_{l}\right)$ as

$$
\begin{aligned}
& \dot{\omega}_{p}=\dot{\omega}_{r}+\dot{\omega}_{p r}=\frac{M_{r}+M_{p}+M_{l}}{I_{d r}}+\frac{M_{p}+M_{l}}{I_{p}+I_{l}} \\
& \dot{\omega}_{l}=\dot{\omega}_{r}+\dot{\omega}_{l r}=\frac{M_{r}+M_{p}+M_{l}}{I_{d r}}+\frac{M_{l}+M_{p}}{I_{p}+I_{l}} . \\
& \dot{\omega}_{r}=\frac{\dot{\omega}_{p}+\dot{\omega}_{l}}{2}=\frac{M_{r}+M_{p}+M_{l}}{I_{d r}}
\end{aligned}
$$

\section{Conclusion}

Mathematical model of the mechanical differential is an important component of the complex vehicle drivetrain model. It can be built by different approaches according to the modelled system structure [11 and 12]. This article shows how to build a three-terminal mechanical differential block model calculating the shaft speeds according the acting torques, which is suitable for string structure drivetrain mathematical models. 


\section{References}

[1] DROZDZIEL, P., KOMSTA, H., KRZYWONOS, L.: An Analysis of Unit Repair Costs as a Function of Mileage of Vehicles in a Selected Transport Company. Transport Problems, vol. 9, No. 4, 2014, pp. 73-81.

[2] HANDRIK, M., VASKO, M., KOPAS, P., SAGA, M.: Effective Finite Element Solution and Post-processing for Wide Load Spectrum. Communications - Scientific Letters of the University of Zilina, vol. 16, No. 3A, 2014, pp. 19-26.

[3] SAGA, M., VASKO, M., KOPAS, P., JAKUBOVICOVA, L.: Numerical Algorithm for Beam Residual Stress Identification. Communications - Scientific Letters of the University of Zilina, vol. 16, No. 3A, 2014, pp. 13-18.

[4] DROZDZIEL, P., KRZYWONOS, L.: The Estimation of the Reliability of the First Daily Diesel Engine Start-up During its Operation in the Vehicle. Maintenance and Reliability, 1(41), 2009, pp. 4-10, ISSN 1507-2711.

[5] DROZDZIEL, P., KOMSTA, H., KRZYWONOS, L.: Repair Costs and the Intensity of Vehicle Use. Transport Problems, vol. 8, No. 3, 2013, pp. 131-138.

[6] KOHAR, R., HRCEK, S.: Dynamic Analysis of a Rolling Bearing Cage with Respect to the Elastic Properties of the Cage for the Axial and Radial Load Cases. Communications - Scientific Letters of the University of Zilina, vol. 16, No. 3A, 2014, pp. 74-81.

[7] DROZDZIEL, P., KRZYWONOS, L., MADLENAK, R., RYBICKA, I.: Selected Aspects of Analyses of Failure Rates of Active Safety Systems in Buses. Communications - Scientific Letters of the University of Zilina, vol. 16, No. 3, 2014, pp. 114-119.

[8] KAMPF, R., LIZBETIN, J., LIZBETINOVA, L: Requirements of a Transport System User, Communications - Scientific Letters of the University of Zilina, vol. 14, No. 4, 2012, pp. 106-108.

[9] HRCEK, S., KOHAR, R., MEDVECKY, S.: Determination on the Maximum Roller Bearing Load with Regards to Durability thereof using FEM Analysis. Communications - Scientific Letters of the University of Zilina, vol. 14, No. 3, 2012, pp. 55-61.

[10] SAPIETOVA, A., SAGA, M., NOVAK, P., JAKUBOVICOVA, L.: Multi-software Platform for Solving of Multibody Systems Synthesis. Communications - Scientific Letters of the University of Zilina, vol. 14, No. 3, 2012, pp. 43-48.

[11] BUKOVA, B., BRUMERCIKOVA, E., MADLENAK, R.: Transport and e-commerce. Bratislava : Wolters Kluwer, 2014, 172 p., ISBN 978-80-8168-130-1.

[12] BUKOVA, B., BRUMERCIKOVA, E., KOLAROVSZKI, P.: Spedition and Logistics, Bratislava : Wolters Kluwer, 2014. 318 p., ISBN 978-80-554-0925-2. 